\title{
Prognostic Value of Pathological Characteristics of Colorectal Cancer
}

\author{
F.T. Bosman
}

The overall cure rate of colon cancer has not improved dramatically in the last decade, remaining at approximately $60 \% 5$-year survival. The main reason for this lack of progress is that at the moment the primary tumour is resected, a significant proportion of the patients with seemingly localised disease already has (undetectable) micrometastases, mostly in the liver. The most important prognostic indicators have been extension of the tumour into the bowel wall and the presence of lymph node metastasis, as expressed in the Dukes classification. However, in the Dukes B and C categories, these parameters are poor predictors of final outcome. For improvement of the prognosis, in addition to earlier detection, more aggressive (adjuvant) treatment of high risk patients would be a rational strategy. This requires development of new therapeutic modalities, but also reliable stratification of patients according to high risk or low risk for recurrent disease. In recent years, many attempts have been made to improve the prediction of final outcome. Parameters studied include inflammatory response to the primary tumour, tumour cell growth fraction, tumour cell differentiation, genetic abnormalities and expression of genes involved in invasion and metastasis. Although some of these newer parameters have significant predictive value, in multivariant analyses, most appear to have limited independent value. Recent studies indicate that genetic abnormalities might be important new prognostic indicators. One of the most promising findings in this area is an allelic loss of chromosome 18q, which allows division of Dukes B patients into subgroups with low risk and high risk for recurrent disease.

Key words: colorectal cancer, pathology, prognosis, oncogenes, tumour suppressor genes, invasion, metastasis, proliferation, differentiation

Eur 7 Cancer, Vol. 31A, Nos 7/8, pp. 1216-1221, 1995

\section{INTRODUCTION}

IN THE clinical management of colorectal cancer, the pathologist plays a distinct role. During the diagnostic evaluation of a putative colorectal carcinoma patient, it is the pathologist who makes the final diagnosis, usually on an endoscopic biopsy specimen. This diagnosis will be confirmed through examination of the resection specimen. Of more importance than diagnostic confirmation is the determination of the extent of spread in the bowel wall and in regional lymph nodes. This information is indispensible for staging purposes. Staging is still mostly performed according to the Dukes classification, although the use of a TNM based staging system is becoming more popular. Tumour stage is the most important prognostic parameter. The predictive value of tumour stage, especially in the Dukes B and C categories (which correspond to stages II and III), is rather limited. Therefore, pathologists have explored a variety of possibilities to develop more detailed classification parameters, which would allow reliable prediction of tumour behaviour in the individual patient. Thus, in numerous studies, the prognostic significance of cancer cell differentiation, proliferative activity, expression of invasion and metastasis-related genes and genetic changes, including oncogene and tumour suppressor gene abnor-

Correspondence to F.T. Bosman, Department of Pathology, Erasmus University, P.O. Box 1738, 3000 DR Rotterdam, The Netherlands. malities, have been investigated. It is the purpose of this brief review to critically examine the significance of these new parameters for the clinical management of colorectal cancer.

\section{CONVENTIONAL STAGING}

It is generally recognised that tumour stage, as reflected for example in the Dukes classification, is one of the most powerful predictors of final outcome in colorectal cancer patients [1]. The overall 5-year survival rate of patients with colorectal cancer is approximately $60 \%$. However, this differs greatly for the different stages (Table 1). For stage A (approximately $15 \%$ of patients) 5-year survival exceeds $90 \%$ and, conversely, for Dukes D (approximately $10 \%$ of patients) this figure is between 5 and $10 \%$. For stage $\mathbf{B}$, however, which constitutcs approximately

Table 1. Dukes stage and survival

\begin{tabular}{lcc}
\hline Stage & Proportion (\%) & $\begin{array}{c}5 \text {-year } \\
\text { survival (\%) }\end{array}$ \\
\hline A & 15 & $>90$ \\
B & 35 & 70 \\
C & 50 & 30 \\
D & 10 & $5-10$ \\
\hline
\end{tabular}


$35 \%$ of patients, 5-year survival is $70 \%$ and for Dukes $C$ (about $50 \%$ of patients) this is approximately $30 \%$. The lack of prognostic precision in stages $B$ and $C$ hampers stratification of patients into subgroups which might benefit from additional adjuvant therapy. Pathologists have responded to this problem by introducing new parameters which might have independent prognostic significance. More detailed histological evaluation of the pattern of invasion into the bowel wall or into veins has been advocated. Hase and associates [2] reported that irregular tumour cell budding at the invasive front of the tumour indicates more aggressive behaviour than a straight "pushing" tumour margin. Patients with a budding tumour margin showed 20\% 5year survival against $70 \%$ in patients without budding. Budding frequency rose with Dukes stage, but, when stratified for stage budding remained an independent prognostic variable. Yamazoe and associates [3] investigated the depth of venous invasion as a predictor for liver metastasis. This parameter appeared to predict the occurrence of liver metastasis with high probability, especially in combination with desmoplastic reaction, lymphocytic infiltration and depth of invasion. The extent of lymphocytic infiltration was also taken into account in the classification proposed by Shepherd and associates [4]. The latter classification has gained some popularity, but has not become generally accepted. An important limitation of classifications based upon detailed histopathological criteria is their lack of reproducibility. Parameters, such as depth of venous invasion, budding and even intensity of lymphocytic infiltrate are often difficult to quantitate and, therefore, rather subjectively scored.

An alternative approach towards more refined histopathological classification of tumour stage has been the detailcd scarch for lymph node micrometastases by immunohistochemistry. Large clusters of cancer cells in a lymph node are easy to identify, but a few cancer cells in the marginal sinus might escape microscopical detection. Given the overall importance of lymph node involvement [5], a search for occult lymph node involvement might be a useful approach. Several studies have shown that, by using anti-cytokeratin antibodies, micrometastases can be detected in approximately $25 \%$ of cases that would otherwise have been classified as Dukes $B[6,7]$. What this means in terms of prognosis is less clear. Jeffers and colleagues [6] found no correlation between immunohistochemically identifiable micrometastases and age, sex, tumour size, tumour sitc or tumour differentiation, and no prognostic value for this parameter. Greenson and associates [7] found higher survival in Dukes B patients without lymph node micrometastases, although the number of patients they studied was rather limited. This issue is, therefore, not yet resolved and deserves to be analysed further.

\section{TUMOUR DIFFERENTIATION}

By convention, in the histopathological evaluation of a colorectal carcinoma, the tumour is graded. In grading, cytonuclear features including nuclear pleomorphism, hyperchromasia and mitotic activity are taken into account. Furthermore, architectural features are assessed, which implies appraisal of the tendency of cancer cells to form differentiated structures, such as tubules, as well as cell polarity and mucin production. Conventional grading is performed in three categories: well, moderately well and poorly differentiated. Tumour grading has appeared to be somewhat subjective and not very reproducible. As a consequence, the prognostic relevance of tumour grade has tended to be rather limited [4]. Recent attempts to improve tumour grading have taken specific features of cancer cell differentiation into account. To this end, histochemical staining of specific cell types has been the most frequently used approach. Mucin production (indicative of goblet cell differentiation) can be demonstrated through conventional mucin stains. Columnar cells display immunoreactivity for secretory component and brush border-associated proteins, such as villin or sucraseisomaltase. Endocrine cells are chromogranin A immunoreactive. Predominantly, the results of mucin staining and of staining for columnar cell-associated antigens has not yielded important new possibilities, although combinations of these antigens have been shown to convey some prognostically relevant information [8]. An interesting finding has been the detection of a subgroup of tumours with endocrine cells, as reflected in immunoreactivity for chromogranin A [9]. It has been shown that tumours with endocrine cells behave more aggressively than those without this characteristic, especially in the Dukes C category [9]. It is presently unclear what causes this difference. It has been proposed that carcinomas with endocrine cells consist of relatively primitive pluripotent cells which might be more aggressive. Alternatively, neurohormonal peptide production in a carcinoma might provide a paracrine growth stimulus.

\section{TUMOUR CELL PROLIFERATION}

In most malignant neoplasms, a correlation appears to exist between proliferative activity in the tumour and patient survival. Proliferative activity can be histologically assessed by counting mitoses, but because the $M$-phase is only a very short window in the total cell cycle, mitotic counts appear to be somewhat inaccurate. More recent approaches encompass the determination of S-phase fraction by DNA-flow cytometry, metabolic labelling of DNA-synthesising cells using $\left[{ }^{3} \mathrm{H}\right]$ thymidine [10] or bromodeoxyuridine and immunohistochemical staining of cell cycle related gene expression. Popular cell cycle-related antigens are proliferative cell nuclear antigen (PCNA, a DNA polymerase related protein [11]) and the Ki67 antigen. The flow cytometric determination of S-phase fraction seems to be a relatively simple measure of proliferative activity. This technique, however, has two important limitations. Firstly, in carcinomas with multiple aneuploid stemlines in addition to diploid cells, it is not easy to determine the $S$-phase fraction on the basis of solid criteria. Secondly, most flow cytometric analyses are performed on matcrial retrieved from paraffin sections [12]. The precision of DNA measurement is limited in this type of material, and hence reliable S-phase fractions cannot be determined. In spite of these limitations, correlations between S-phase fraction and tumour behaviour have been found. Schutte and colleagues [13] reported a worse outcome in Dukes B patients with an S-phase fraction exceeding $15 \%$.

A much more popular approach towards proliferation analysis is immunohistochemical staining for PCNA or the Ki67 antigen. The latter is the favoured technique since, with the introduction of the MIB-1 antibody, this antigen can also be stained in paraffin sections (Figure 1). Mayer and associates [14] and AlShebener and associates [15] recently reported on the prognostic significance of PCNA expression. In both studies, a multivariant analysis was included. The data indicate that the percentage of PCNA positive cells is an independent predictor of tumour behaviour, the higher PCNA index indicating a shorter survival. Silvestrini and colleagues [10] showed, by $\left[{ }^{3} \mathrm{H}\right]$ thymidine labelling of metastatic colon cancer cells in the liver, that even when liver metastases are present cell proliferation may be a useful prognostic marker. Thus, proliferative activity as reflected in a PCNA index or (preferably) a Ki67 index (using the MIB-1 


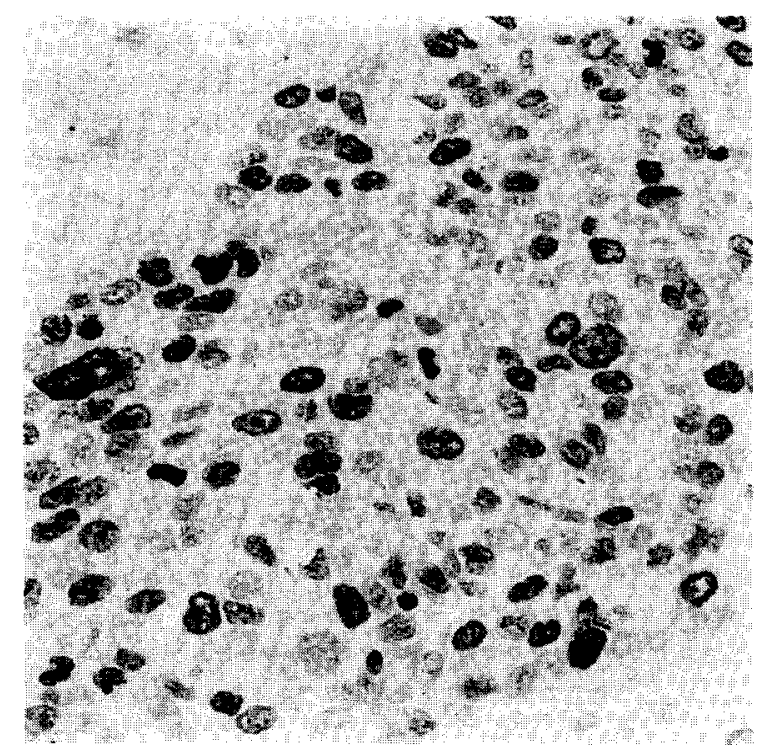

Figure 1. Immunohistochemical staining of the proliferation associated antigen Ki67 (using the MIB-1 antibody) in a poorly differentiated carcinoma of the colon. Most cancer cell nuclei are positive, indicative of a high growth fraction $(\times 400)$.

antibody) might be used as an additional parameter for clinical decision-making.

\section{TUMOUR INVASION AND METASTASES}

For tumour subclassification, much attention has been paid to parameters which are related to invasive and metastatic behaviour. This has been done using histological parameters such as tumour "budding" [2], venous invasion [3] and lymph node micrometastasis $[5,6]$. More recent possibilities include the detection of basement membrane deposits [16], the expression of proteases involved in tumour cell invasion [17, 18], the expression of metastasis-related genes such as the $n m 23$ gene [19], and the expression of cell adhesion molecules [20], including variant forms of CD44 [21].

Havenith and associates [16] studied the prognostic significance of basement membrane staining in colorectal cancer. These investigators noted that, in the tumour periphery, cancer cells did not have a basement membrane, but in the tumour centre a variable amount of this material was deposited. Increasing basement membrane deposition correlated with better prognosis. These authors postulated that the host response to the tumour is reflected in the extent of deposition of extracellular matrix.

The prognostic value of the expression of matrix proteases was recently studied by Mulcahy and colleagues [18] and by Ganesh and colleagues [17]. Mulcahy's group [18] stained colorectal cancer tissues for the urokinase type plasminogen activator (UPA). In Dukes B patients, high grade uPA staining indicated a high probability of the development of liver metastases. Ganesh and associates [17] measured levels of the different components of the plasminogen activator/plasmin system (including uPA, $t$ (tissue type)PA, and the inhibitors PAI-1 and PAI-2) in normal and cancer tissue by immunoassay. These authors found the ratio of uPA in cancer tissue/tPA in normal mucosa and the PAI-2 level in cancer tissue to be independent prognostic variables. It seems, therefore, that determination of matrix proteases might be useful in the development of new subclassifications of colorectal cancer with prognostic value.

In search of new markers for metastatic disease, the $n m 23$ gene has received wide attention (see MacDonald and associates, pp. 1096-1100). This gene was discovered through the generation of a monoclonal antibody which differentially labelled metastatic and non-metastatic melanoma cells. Recently, loss of the $n m 23$ gene has been reported to correlate with the occurrence of distant metastases in colorectal cancer [19]. For colorectal cancer, the $n m 23$ findings have been somewhat conflicting, however, and consequently this finding needs to be further confirmed.

Another area of promising development has been that of cell adhesion molecules. On the assumption that loss of intercellular adhesion would precede cancer cell invasion, the expression of the crucial epithelial cell adhesion molecule, E-cadherin, has been studied in colorectal cancer [20]. It has become clear that E-cadherin expression is highly correlated with tumour differentiation (Figure 2), and may not be an independent prognostic variable. Another limitation of E-cadherin as an invasion marker is that loss of expression of a few cells is much more difficult to detect (let alone to quantitate) than overexpression. This limitation is not shared by the CD44 family of adhesion molecules. CD44 is widely expressed on leucocytes and serves as a leucocyte adhesion molecule, with a regulating function in leucocyte traffic. Following cloning of the CD44 gene, it was discovered that this gene can be alternatively spliced, which results in a family of related proteins derived from a single gene. Subsequent studies have shown that the variant (alternatively spliced) forms of the CD44 molecule are expressed in specific patterns on normal and neoplastic epithelial cells. The v6 variant was shown to be expressed on a subgroup of colorectal carcinomas (Figure 3), and it was established that v6 expression is strongly correlated with tumour progression [21]. Although prospective testing of the clinical use of CD44 v6 staining is still not complete, it is expected that this might become an important new prognostic marker in colorectal cancer.

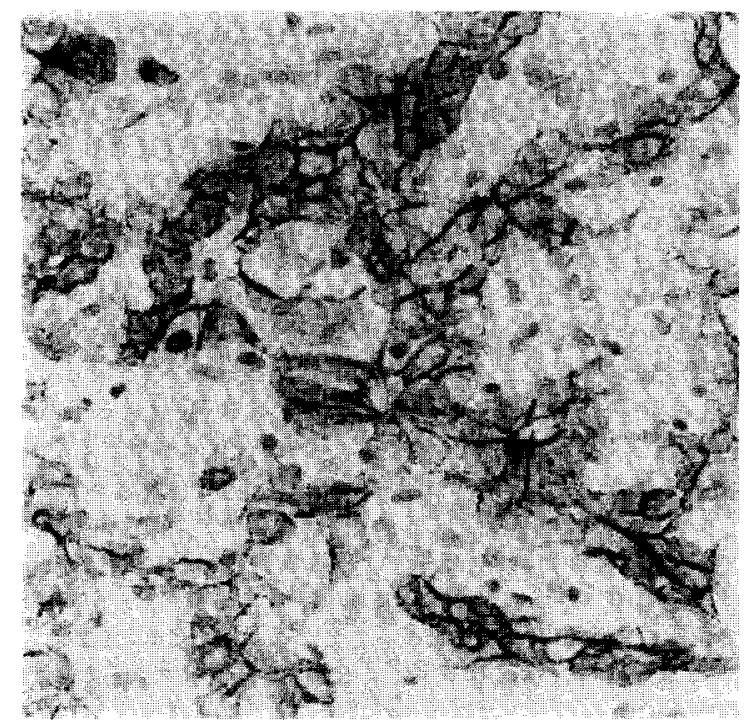

Figure 2. E-cadherin immunoreactivity in a moderately differentiated adenocarcinoma. Irregular cell strands show intense intercellular staining $(\times 400)$. 


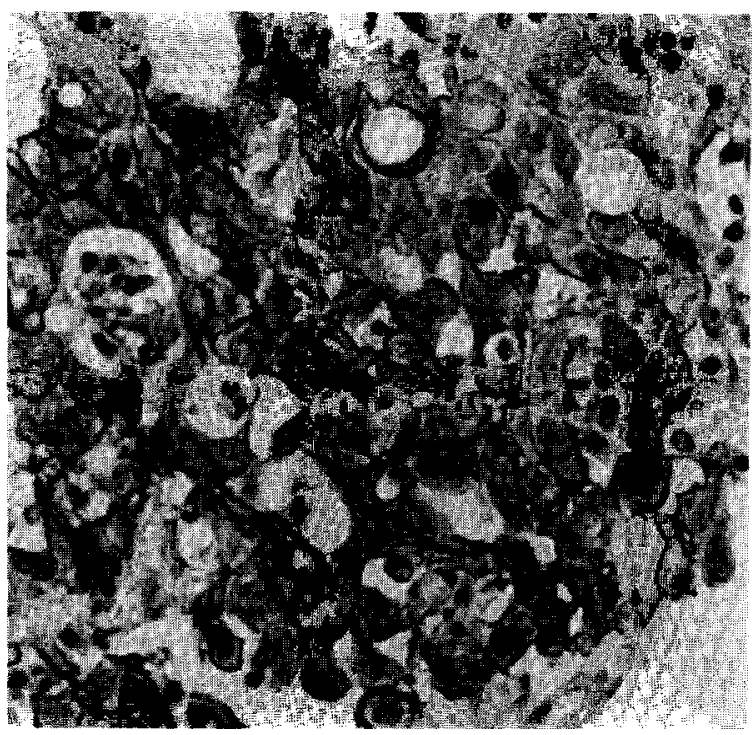

Figure 3. CD44 (v6) immunoreactivity in a moderately differentiated adenocarcinoma. Focally the tumour cells show intense intercellular staining $(x$ 400).

\section{TUMOUR CELL GENETICS}

No solid tumour has been studied as intensely as colorectal cancer for molecular genetic abnormalities. The pioneering work of Vogelstein and collaborators led to the definition of a series of molecular genetic abnormalities which together determine the neoplastic phenotype of a colorectal cancer cell [22]. Although well accepted in cancer cell biology, the clinical use of this molecular genetic model of colorectal carcinogenesis remains to be established.

Clinical testing of gross genetic abnormalities, as reflected in an abnormal DNA content of the cancer cells which can be determined by DNA flow cytometry, has been reported repeatedly $[23,24]$. Ploidy analysis is relatively simple and fast, and could, therefore, be of practical use if it would provide a strong independent new predictor for prognosis. Most studies, to date, indicate that patients with aneuploid tumour cell populations, in general, have a shorter survival than patients with diploid tumours. Tumour ploidy, however, is significantly correlated with other prognostically relevant variables, including Dukes stage, tumour grade and proliferative activity, and, therefore, as an independent prognostic indicator, ploidy has appeared of limited value $[23,24]$.

Although technically more complex, detailed molecular genetic analysis of colorectal cancer in search of prognostically relevant parameters could potentially yield highly valuable information which could be used in clinical management. Recent developments in this methodology have allowed the use of even paraffin-embedded archival material for molecular genetic analysis [25]. The oncogenes and tumour suppressor genes of interest for the study of colorectal cancer can be directly inferred from Vogelstein's model of colorectal carcinogenesis [22]. KIRAS oncogene mutations are assumed to function early in colorectal carcinogenesis. Consequently, KI-RAS mutations are found in a high percentage of colorectal cancers. It was even recently shown that in precancerous conditions as well as in inflammatory bowel disease without overt dysplasia $K I-R A S$ mutations may occur [26]. In spite of their putative early role in colorectal carcinogenesis, KI-RAS mutations appeared to be independent predictors of unfavourable outcome in several studies $[27,28]$.

Interesting observations on the pattern of mutations on codon 12 of the KI-RAS were recently reported by Moerkerk and associates [28]. These authors observed only G- $>$ A mutations in Dukes $B$, but predominantly $\mathrm{G}->\mathrm{C}$ or $\mathrm{G}->\mathrm{T}$ mutations in Dukes $\mathrm{C}$ tumours. This observation suggests that a Dukes $\mathrm{C}$ tumour is not merely a later stage of progression of a Dukes $B$ tumour, but possibly a different tumour subgroup with a different pathway of molecular carcinogenesis. This possibility, however, needs to be confirmed.

Bell and associates [27] investigated the predictive value of codon-12 KI-RAS mutations for patient survival. This parameter appeared not to have any prognostic significance as an independent variable. When taken together with TP53 overexpression, as detected by immunocytochemistry, KI-RAS mutations identified a subgroup of patients with shorter survival.

Abnormalities in the TP53 gene have received ample attention in colorectal cancer research. In the Vogelstein model, TP53 is postulated to function late in colorectal carcinogenesis. This is in agreement with the observation that with increasing dysplasia in adenomas the percentage of cases with TP53 abnormalities rises. Of all colorectal carcinomas, approximately $70 \%$ show TP53 abnormalities. In a PCR-based study, Hamelin and associates [29] convincingly demonstrated a strong correlation between the presence of TP53 mutations and shorter survival. In multivariate analysis, this parameter appeared to be independent from other prognostic variables. Mutations of TP53 can also be detected by immunocytochemistry because the mutated proteins appear to have a prolonged half-life, which leads to their accumulation in the nuclei of mutated cells (Figure 4). Yamaguchi and colleagues [30] studied the prognostic significance of TP53 overexpression by immunocytochemistry. In primary tumours, TP53 expression was not correlated with any other histological variable. However, patients with a TP53 positive tumour showed a higher risk of developing liver metastases. Accordingly, in the Dukes C category, TP53 overexpression appeared to be a highly significant predictor of prognosis in terms of the 5-year survival rate.

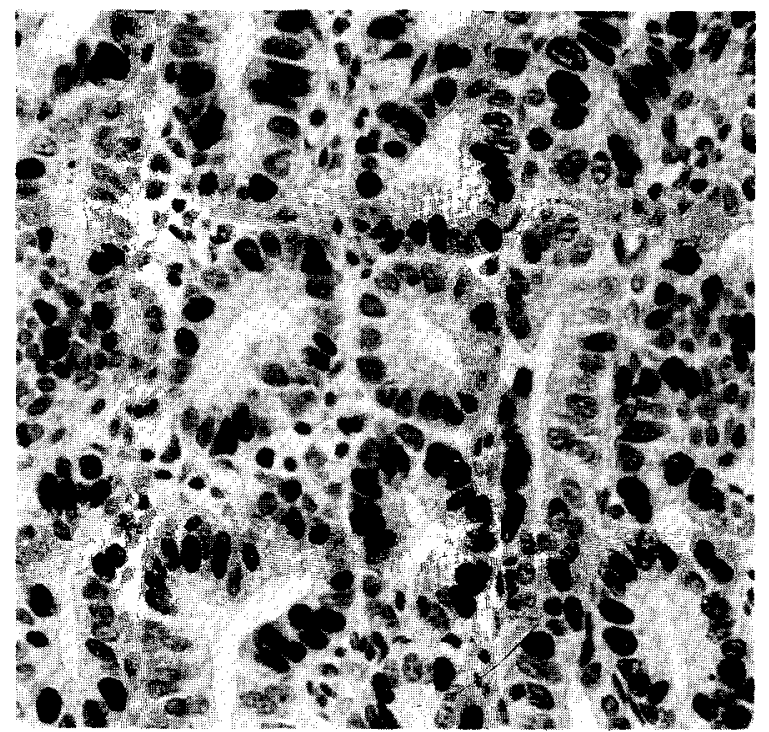

Figure 4. Immunostaining for p53 in a well differentiated carcinoma $(\times 400)$. 
In a recent study, Jen and colleagues [25] reported on the significance of allelic loss of chromosome $18 \mathrm{q}$ in colorectal cancer. These authors investigated 18q status using polymorphic microsatellite markers in a PCR-based assay on paraffinembedded tissue. Chromosome $18 \mathrm{q}$ was chosen in view of the fact that it is frequently delcted in colon cancer (hence the namc of the associated oncogene: deleted in colon cancer or $D C C$ ). Of all tumours, $67 \%$ showed $18 \mathrm{q}$ allelic loss. With increasing stage, the frequency of allelic loss also increased. Tumours with allelic loss were often $(70 \%)$ located in the right side of the colon. When stratified for stage, $18 \mathrm{q}$ allelic loss was strongly correlated with survival in stage II (which corresponds with Dukes B) patients. In fact, stage II patients could be divided according to $18 \mathrm{q}$ allelic loss into a subgroup which behaved as stage I (no loss) and a subgroup which behaved as stage III (loss). In view of the high probability of the existence of correlations between the different prognostic parameters, a multiple regression analysis was performcd. In all models, 18q allclic loss had a highly significant independent effect on prognosis.

\section{CONCLUSION}

In reviewing the available data concerning pathological characteristics of colorectal cancer (Table 2) it is clear that conventional anatomical (depth of invasion, lymph node involvement, liver metastases) and histological parameters (vascular and perineural invasion, lymphocyte infiltration and to a lesser extent tumour differentiation) continue to provide a solid basis for the purposes of prognosis. It is also clear, however, that improvement in the prognosis of colorectal carcinoma will have to come either from carlier detection and secondary prevention or from more effective therapy. For more effective therapy, adjuvant treatment modalities are available and more effective new modalities are being, or will be, developed. Reliable stratification of particularly Dukes B and C (or stages II and III) patients into subgroups with low and high risk of recurrent disease will be essential. This is where pathology will have its most significant impact on the clinical management of colorectal cancer. Prognostic factors, however, will only become clinically significant when they are used in clinical decision-making. The clinical use of prognostic factors should be assessed in

Table 2. Pathological parameters with prognostic significance

\begin{tabular}{|c|c|c|}
\hline Category & Parameter & $\begin{array}{l}\text { Prognostic } \\
\text { significance }\end{array}$ \\
\hline Anatomical & $\begin{array}{l}\text { Depth of invasion } \\
\text { Lymph node metastasis } \\
\text { Liver metastasis } \\
\text { Differentiation }\end{array}$ & $\begin{array}{l}\text { Strong } \\
\text { Strong } \\
\text { Strong } \\
\text { Weak }\end{array}$ \\
\hline Proliferation & $\begin{array}{l}\text { S-phase fraction } \\
\text { Proliferation markers (PCNA, Ki67) }\end{array}$ & $\begin{array}{l}\text { Weak } \\
\text { Weak }\end{array}$ \\
\hline $\begin{array}{l}\text { Invasion and } \\
\text { metastasis }\end{array}$ & $\begin{array}{l}\text { Basement membranes } \\
\text { uPA/plasmin system } \\
n m 23 \\
\text { E-cadherin } \\
\text { CD44 }\end{array}$ & $\begin{array}{l}\text { Weak } \\
\text { Weak } \\
\text { Weak } \\
\text { Weak } \\
\text { Strong }\end{array}$ \\
\hline $\begin{array}{l}\text { Molecular } \\
\text { genetics }\end{array}$ & $\begin{array}{l}\text { Ploidy } \\
K I-R A S \\
T P 53 \\
18 \mathrm{q} \text { loss }\end{array}$ & $\begin{array}{l}\text { Weak } \\
\text { Weak } \\
\text { Weak } \\
\text { Strong }\end{array}$ \\
\hline
\end{tabular}

prospective studies. The most promising new prognostic factors have resulted from cancer cell genetics. With the advent of techniques to identify reliably, even in routinely processed tissue specimens, relevant molecular genetic characteristics of tumour cells, it may be expected that, in terms of predicting outcome in individual patients, enormous progress will be made in the coming years. As yet, the basis of tumour classification will remain classical histopathology, but molecular pathology will contribute scientifically exciting and clinically relevant new information.

1. Deans GT, Parks TG, Rowlands BJ, Spence RAJ. Prognostic factors in colorectal cancer. BrF Surg 1992, 79, 608-613.

2. Hase $\mathrm{K}$, Shatney C, Johnson D, et al. Prognostic value of tumor "budding" in patients with colorectal cancer. Dis Colon Rectum $1993,36,627-635$.

3. Yamazoe $\mathrm{Y}$, Maetani S, Onodera $\mathrm{H}$, Nishikawa $\mathrm{T}$, Tobe $\mathrm{T}$. Histopathological prediction of liver metastasis after curative resection of colorectal cancer. Surg Oncol 1992, 1, 237-244.

4. Shepherd NA, Saraga EP, Love SB, Jass JR. Prognostic factors in colonic cancer. Histopathology 1989, 14, 613-620.

5. Newland RC, Dent OF, Lyttle MN, Chapuis PH, Bokey EL. Pathologic determinants of survival associated with colorectal cancer with lymph node metastases. A multivariate analysis of 579 patients. Cancer 1994, 73, 2076-2082.

6. Jeffers MD, O'Dowd GM, Mulcahy H, Stagg M, O'Donoghue DP, Toner $M$. The prognostic significance of immunohistochemically detected lymph node micrometastases in colorectal carcinoma. $\mathcal{f}$ Path 1994, 172, 183-187.

7. Greenson JK, Isenhart CE, Rice R, Mojzisik C, Houchens D, Martin EW. Identification of occult micrometastases in pericolic lymph nodes of Dukes B colorectal cancer patients using monoclonal antibodies against cytokeratin and CC49. Correlation with longterm survival. Cancer 1994, 73, 563-569.

8. Ho SB, Itzkowitz SH, Friera AM, Jiang SH, Kim YS. Cell lineage markers in premalignant and malignant colonic mucosa. Gastroenterology 1989, 97, 392-404.

9. Bruine de AP, Wiggers T, Beek C, et al. Endocrine cells in colorecta adenocarcinomas: incidence, hormone profiles and prognostic relevance. Int 7 Gancer 1993, 54, 765-771.

10. Silvestrini R, Costa A, Faranda A. Cell kinetics of colorectal liver metastases. Dis Colon Rectum 1994, 37, S92-95.

11. Tanaka $M$, Omura $K$, Watanabe $Y$, et al. Prognostic factors of colorectal cancer: $K$ ras mutation, overexpression of the $p 53$ protein, and cell proliferative activity. 7 Surg Oncol 1994, 57, 57-64.

12. Yamazoe $Y$, Maetani $S$, Nishikawa $T$, Onodera $H$, Tobe $T$, Imamura $M$. The prognostic role of the DNA ploidy pattern in colorectal cancer analysis using paraffin-embedded tissue by an improved method. Surg Today 1994, 24, 30-36.

13. Schutte B, Reijnders MMJ, Wiggers TH, et al. Retrospective analysis of the prognostic significance of DNA content and proliferative activity in large bowel carcinomas. Cancer Res 1987, 47, $5494-5496$

14. Mayer A, Takimoto M, Fritz E, Schellander G, Kofler K, Ludwig $H$. The prognostic significance of proliferating cell nuclear antigen, epidermal growth factor receptor, and $m d r$ gene expression in colorectal cancer. Cancer 1993, 71, 2454-2460.

15. Al-Shebener IF, Shibata HR, Sampalis J, Jothy S. Prognostic significance of proliferating cell nuclear antigen expression in colorectal cancer. Cancer 1993, 71, 1954-1959.

16. Havenith MG, Arends JW, Simon R, Volovics A, Wiggers TH, Bosman FT. Type IV collagen immunoreactivity in colorectal cancer. Prognostic value of basement membrane deposition. Cancer $1988,62,2207-2211$.

17. Ganesh S, Sier CF, Griffioen G, et al. Prognostic relevance of plasminogen activators and their inhibitors in colorectal cancer. Cancer Res 1994, 54, 4065-4071.

18. Mulcahy HE, Duffy MJ, Gibbons D, et al. Urokinase-type plasminogen activator and outcome in Dukes' B colorectal cancer. Lancet 1994, 344, 583-584.

19. Cohn KH, Wang F, DeSoto-LaPaix F, et al. Association of nm23-H1 allelic deletions with distant metastases in colorectal carcinoma. Lancet 1991, 338, 722-724. 
20. Nigam AK, Savage FJ, Boulos PB, Stamp GWH, Liu D, Pignatelli $M$. Loss of cell-cell and cell-matrix adhesion molecules in colorectal cancer. BrF Cancer 1993, 68, 507-514.

21. Wielenga VJ, Heider KH, Offerhaus GJ, et al. Expression of CD44 variant proteins in human colorectal cancer is related to tumor progression. Cancer Res 1993, 53, 4754-4756.

22. Fearon ER, Vogelstein B. A genetic model for colorectal tumorigenesis. Cell 1990, 61, 759-767.

23. Deans GT, Williamson $K$, Hamilton $P$, et al. DNA densitometry of colorectal cancer. Gut 1993, 34, 1566-1571.

24. Bottger TC, Potratz D, Stockle M, Wellek S, Klupp J, Junginger T. Prognostic value of DNA analysis in colorectal carcinoma. Cancer $1993,72,3579-3587$.

25. Jen J, Kim H, Piantadosi S, et al. Allelic loss of chromosome $18 \mathrm{q}$ and prognosis in colorectal cancer, $N$ Engl $\mathcal{F}$ Med 1994, 331, 213-221.
26. Chaubert $P$, Benhatter J, Saraga $E$, Costa J. K-ras mutations and p53 alterations in neoplastic and non-neoplastic lesions associated with longstanding ulcerative colitis. Am f Path 1994, 144, 767-775.

27. Bell SM, Scott N, Cross D, et al. Prognostic value of p53 overexpression and c-Ki-ras gene mutations in colorectal cancer. Gastroenterology 1993, 104, 57-64.

28. Moerkerk P, Arends JW, Van Driel M, De Bruine A, De Goey A, Ten Kate J. Type and number of $\mathrm{Ki}$-ras point mutations relate to stage of human colorectal cancer. Cancer Res 1994, 54, 3376-3378.

29. Hamelin R, I aurent-Puig P, Olschwang S, et al. Association of p53 mutations with short survival in colorectal cancer. Gastroenterology $1994,106,42-48$.

30. Yamaguchi A, Nakagawara G, Kurosaka $Y$, Nishimura G, Yonemura Y, Miyazaki I. p53 immunoreaction in endoscopic biopsy specimens of colorectal cancer, and its prognostic significance. $B r \mathcal{F}$ Cancer 1993, 68, 399-402. 